\section{Hypoallergene Säuglingsnahrung: Schutz bis ins Schulalter?}

Spezielle Hydrolysat-Nahrung senkt bei allergiegefährdeten Säuglingen, die nicht (voll) gestillt werden können, das Risiko für eine atopische Dermatitis. Das Erkrankungsrisiko der Kinder ist bis zum zehnten Lebensjahr reduziert.

Z wischen 1995 und 1998 wurden insgesamt 2.252 Säuglinge in die German Infant Nutritional Intervention (GINI)-Studie einbezogen. Falls die Kinder nicht (ausschließlich) gestillt werden konnten, standen verschiedene Säuglingsnahrungen zur Verfügung: partiell oder extensiv hydrolysierte Formula auf Molkebasis (pHF-M, eHF-M), extensiv hydrolysierte Formula auf Kaseinbasis (eHF-K) oder konventionelle KuhmilchFormula, KMF).

Die Intention-to-Treat-Analyse (ohne Berücksichtigung, ob und wie viel der vorgesehenen Nahrung die Kinder tatsächlich erhalten hatten) ergab folgende Ergebnisse: Das kumulative Zehn-Jah-
res-Risiko für eine allergische Erkrankung in den Gruppen mit pHF-M und eHF-K war im Vergleich zur konventionellen Säuglingsnahrung auf Kuhmilchbasis signifikant um $13 \%$ bzw. um $17 \%$ reduziert. Verantwortlich dafür waren vor allem die geringeren Raten an atopischen Dermatitiden. Der Effekt von eHF-M auf Allergien und Neurodermitis blieb unter $10 \%$. Auf das Risiko von Asthma und allergischer Rhinitis hatte keines der Hydrolysate einen signifikanten Effekt.

Stärker ausgeprägt war der Schutz vor atopischer Dermatitis durch die Hydrolysat-Nahrung, wenn nur die Daten der Kinder ausgewertet wurden, die tatsäch- lich die vorgesehene Studienformula erhalten haben (Per-Protocol-Analyse). Das Erkrankungsrisiko war mit pHF-M um $33 \%$ und mit eHF-K um $42 \%$ reduziert, während der Effekt von eHF-M nur eine grenzwertig signifikante Reduktion zeigte.

Fazit: „Unsere Ergebnisse stützen die derzeitigen Empfehlungen, bei Hochrisiko-Säuglingen bestimmte KuhmilchHydrolysate zu verwenden“, unterstreichen die Autoren. Dadurch werde das kumulative Risiko für eine atopische Dermatitis, nicht aber für allergische Erkrankungen der Atemwege, bis zum Alter von zehn Jahren gesenkt.

Dr. Beate Schuhmacher

Von Berg A et al. Allergies in high-risk schoolchildren after early intervention with cow's milk protein hydrolysates: 10-year results from the German Infant Nutritional Intervention (GINI) study. J Allergy Clin Immunol 2013 Mar 15; Epub ahead of print

\section{Kutane Paraneoplasie}

Ein 55-jähriger Mann litt seit einem Jahr an Schluckbeschwerden. Er hatte fast 7 kg Gewicht verloren und war ständig heiser. Sowohl der Vater als auch ein Onkel väterlicherseits waren an einem Ösophaguskarzinom erkrankt.

n Händen und Füßen des Patienten fielen Trommelschlegelfinger und

ein palmoplantares Keratoderm auf. Der Vater des Patienten hatte ähnliche
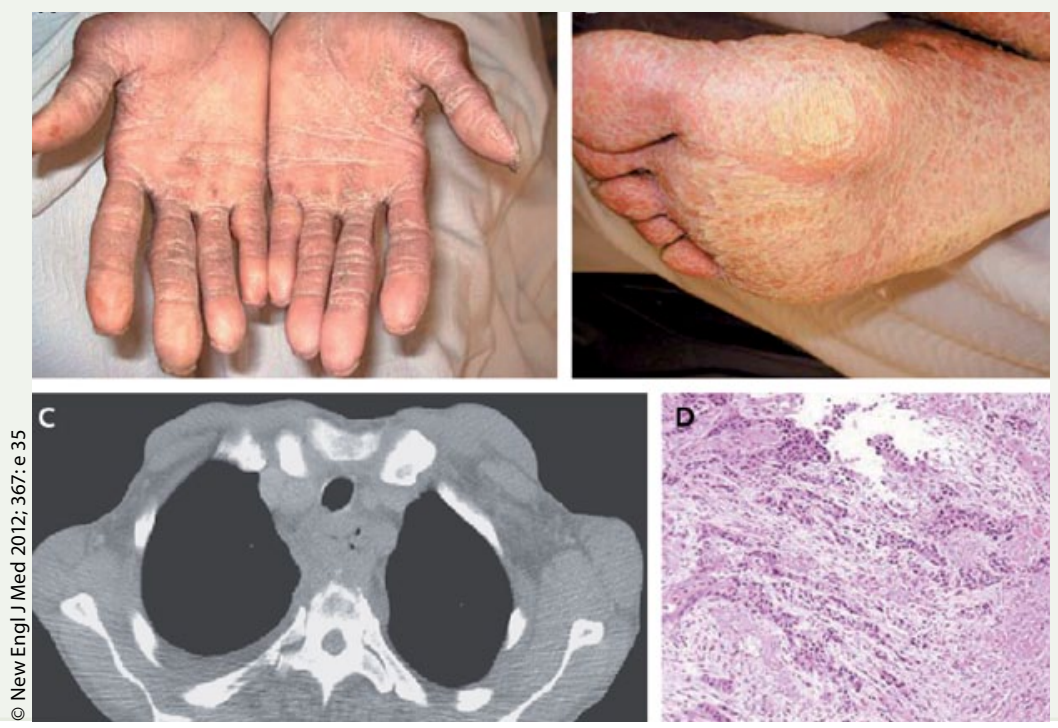

Hautveränderungen an Händen und Füßen.

Im CT des Thorax zeigte sich eine zirkumferenziell wachsende Raumforderung im Bereich des proximalen Ösophagus. Histologisch ergab sich ein invasiv wachsendes, gering differenziertes Plattenepithelkarzinom.

Eine Tylosis und ein Plattenepithelkarzinom des Ösophagus sind beim Auftreten in mehreren Generationen Kriterien für das sog. Howell-EvensSyndrom, einem seltenen, wahrscheinlich autosomal-dominant vererbten Krankheitsbild.

Der Zustand des Patienten verschlechterte sich während des stationären Aufenthalts rasch und er starb an einer Aspiration, noch ehe weitere therapeutische Schritte eingeleitet werden konnten.

H.-S. FüessI

Lea Z-E, Wodiri A. Palmoplantar keratoderma associated with esophageal cancer. New Engl J Med 2012; 367: e 35 